\title{
Cyclic AMP-Induced Slow Inward Current: Its Synaptic Manifestation in Aplysia Neurons
}

\author{
JacSue Kehoe \\ Laboratoire de Neurobiologie, Ecole Normale Supérieure, 75005 Paris, France
}

Three presynaptic neurons, monosynaptically connected to the medial cells of the pleural ganglion of Aplysia californica and previously shown to elicit CAMP-mediated diminutions in $K$ conductance in those cells (Kehoe, 1985a, b), were shown to elicit still another slow synaptic current that resembles the CAMP-induced cationic current described in the preceding paper (Kehoe, 1990). The synaptic current elicited by these so-called "blocking" neurons was compared, in hyperpolarized medial cells, with the current induced by an intracellular injection of cAMP. It was found that (1) both currents show an outward rectification, (2) both currents are enhanced and prolonged by phosphodiesterase inhibitors (as well as by intracellular acidification of the postsynaptic neuron and by bath-applied caffeine), and (3) both currents react in the same way to changes in $(\mathrm{Ca})_{0}$, showing a net enhancement when $(\mathrm{Ca})_{0}$ is reduced and, conversely, a marked diminution when extracellular $(\mathrm{Ca})_{0}$ is increased. The increase in amplitude of the slow synaptic current in low-Ca solutions and its decrease in high-Ca seawater are contrary to the changes that would be expected from the known effects of $\mathrm{Ca}$ on transmitter release at chemical synapses, revealing the overriding importance of the postsynaptic block by Ca.

The data presented here strongly suggest that both the slow inward current and the diminutions in $K$ conductance induced by the firing of the 3 blocking neurons are mediated by CAMP. Like the 2 cAMP-mediated diminutions in $K$ conductance (Kehoe, 1985a, b), the cAMP-activated slow inward current, because of its atypical voltage dependence, both depolarizes the medial cell and causes an increase in its input resistance at resting potential. Consequently, the synaptically activated increase in CAMP prolongs the excitability of the medial cells for up to tens of seconds after the end of presynaptic firing.

A slow inward current induced by cAMP in central molluscan neurons was noted as early as 1975 (see Liberman et al., 1975) and has been the object of many investigations since that time (for references, see Kehoe, 1990). The ionic and pharmacological characteristics of that response were described in detail in the preceding paper (Kehoe, 1990). As ubiquitous as that response appears to be, its activation by neurotransmitters has

Received Oct. 16, 1989; revised Mar. 15, 1990; accepted May 2, 1990.

This work was supported by the CNRS (URA 295), the INSERM (CRE 886005), and the Universite Pierre et Marie Curie.

Correspondence should be addressed to JacSue Kehoe, Laboratoire de Neurobiologie, Ecole Normale Supérieure, 46 rue d'Ulm, 75005 Paris, France.

Copyright (C) 1990 Society for Neuroscience $0270-6474 / 90 / 103208-11 \$ 03.00 / 0$ only recently been demonstrated (Matsumoto et al., 1988; Taussig et al., 1989; see also Ichinose and McAdoo, 1988, 1989), and its synaptic activation has yet to be documented.

In the medial cells of the pleural ganglion of Aplysia californica, it has previously been shown that cAMP diminishes 2 distinct $\mathrm{K}$ conductances: one activated by $\mathrm{ACh}$, the other by intracellular Ca (Kehoe, 1985a, b). It was also demonstrated that these cAMP-induced diminutions in $\mathrm{K}$ conductance could be elicited by 3 identifiable neurons monosynaptically connected to the medial cells. In this paper, it is shown that the same presynaptic neurons that block the $\mathrm{K}$ conductances also elicit the CAMP-induced slow inward current referred to above and analyzed in the preceding paper (Kehoe, 1990). This synaptic response, like the synaptically activated diminutions in $\mathrm{K}$ conductance, causes a long-lasting depolarization of the unclamped medial cells that is coupled with an increased input resistance, thereby increasing the excitability of those cells for tens of seconds, sometimes minutes.

Some of the data described in this paper were presented to the Socicty for Neuroscience (Kehoe, 1986).

\section{Materials and Methods}

Preparation. The experiments described in this paper were performed on the so-called medial cells of the pleural ganglia of Aplysia californica and on 4 identifiable presynaptic neurons monosynaptically connected to those cells (I, II, III, and V; presynaptic neuron IV was not used in these experiments; for a description of the preparation, see Kehoe, $1972 \mathrm{~b}$, 1985a).

Experimental procedures. All information concerning the composition of bath solutions, replacement of ions, and application of drugs were presented in the preceding paper (Kehoe, 1990). Double-barreled electrodes were used for intracellular ionophoresis of either the $\mathrm{Na}$ salt of cAMP $(0.25 \mathrm{~m})$ or $\mathrm{HCl}$ in the medial cells, as well as for that of tetraethylammonium (TEA)Cl in the presynaptic neurons (see text relating to Fig. $8 B$ ). The second barrel was always filled with $\mathrm{K}_{2} \mathrm{SO}_{4}$, and currents were generated by a WPI microionophoresis unit. Parameters of the specific injection currents are given in the figure legends. A description of the electrodes, voltage clamp design, and recording procedures has been published previously (Kehoe, 1985a).

Methodological considerations. The rate and duration of firing of the presynaptic neurons were continually evaluated and adjusted so that both the firing rate and the number of presynaptic action potentials were maintained constant from one stimulation to the next, over time as well as under different experimental conditions. The interstimulus intervals were chosen to insure constant amplitude responses to repetitive presynaptic stimulation. None of the pharmacological or ionic manipulations made in the experiments reported here induced spontaneous synaptic input to the normally "silent" medial cells, as measured by the somatically placed recording electrodes. Consequently, the only synaptic input to the cells during the recording period, whether under control or experimental conditions, was that elicited by controlled stimulation of the presynaptic cells (see above). Hence, there was no indication that these manipulations provoked an inadvertent increase in baseline cAMP levels that could explain any of the results obtained here. 

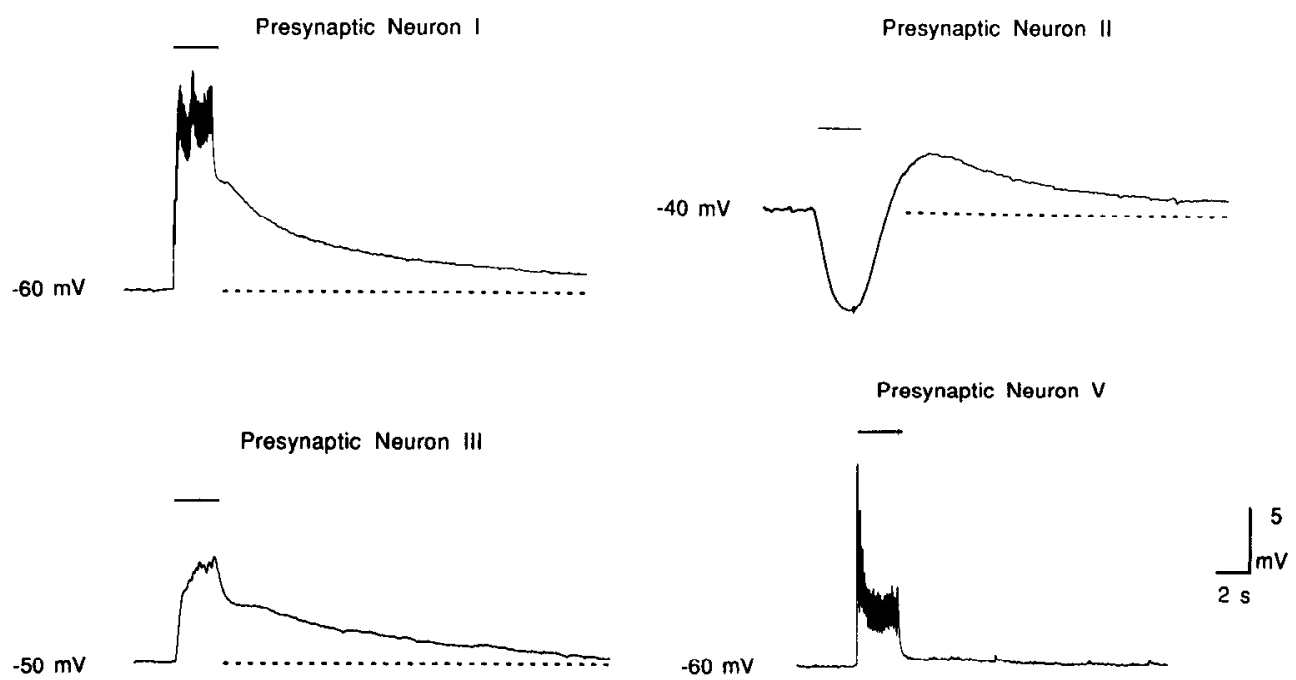

Figure 1. Slow depolarizing responses elicited in unclamped medial cells by the firing of the 3 presynaptic blocking neurons (I-III). All of the presynaptic neurons $(I-I I I, V)$ elicit, with each action potential, a relatively rapid, short latency PSP in the medial cells. These classical PSPs, which can be seen in all 4 records and which terminate with the end of presynaptic firing (see bars over records), are all associated with an increased conductance of the medial cells. Presynaptic neurons I and III elicit excitatory PSPs, with those elicited by presynaptic neuron III being slower than those of presynaptic neuron I; presynaptic neuron II, in contrast, elicits inhibitory PSPs consisting of a rapid Cl-dependent element and a slower K-dependent element that are seen here as a summated hyperpolarizing wave (see $I I$; Kehoe, 1985a). In records $I-I I I$, the classical PSPs are accompanied and followed by a slowly developing, long-lasting depolarizing wave that reaches its maximum amplitude after the termination of presynaptic stimulation. This late depolarization is lacking in the response to the nonblocking presynaptic neuron $(V ;$ Kehoe, $1985 \mathrm{a}$, b), and the membrane potential returns immediately to the preset membrane potential at the end of the presynaptic stimulation. The classical EPSPs elicited by presynaptic neuron $\mathrm{V}$ are characterized by their tendency to diminish in amplitude with repeated firing. To help in the evaluation of the amplitude and duration of the slow depolarizing response, dotted lines indicating the membrane potential prior to presynaptic simulation have been drawn in the records of the responses to the 3 blocking neurons $(I-I I I)$. For recording the responses to firing of cells $I$ and $V$, the medial cells were hyperpolarized to $-60 \mathrm{mV}$ to avoid the generation of action potentials in the postsynaptic cells.

\section{Results}

The manifestation of the synaptically activated slow inward current in unclamped medial cells. The synaptic current to be described here is one of 3 slow excitatory responses elicited in the medial cells by each of 3 identifiable presynaptic neurons (IIII). Two of the 3 excitatory responses reflect cAMP-induced diminutions in specific $\mathrm{K}$ conductances, and the presynaptic neurons have therefore been referred to as "blocking" neurons. Under the conditions of the experiments reported here, however, neither of those 2 responses was present, because neither of the 2 cAMP-sensitive $\mathrm{K}$ conductances was activated. Consequently, only the third type of slow potential was manifest. Figure 1 shows this third slow excitatory potential as elicited by the 3 "blocking" neurons in unclamped, hyperpolarized medial cells. The response is seen as a slow depolarizing wave that accompanies and follows more rapid, so-called "classical" PSPs, the nature of which is specific to the presynaptic cell (see figure legend for details). This prolonged depolarization reaches its peak following the end of presynaptic firing and lasts for several tens of seconds. In contrast, firing of the control neuron, which was previously shown to have no effect on the two $\mathrm{K}$ conductances mentioned above (Kehoe, 1985a, b), and hence not to elicit the 2 previously described slow synaptic potentials, also fails to elicit the slow excitatory potential studied here (see Fig. $1 V$.

The voltage dependence of the synaptically activated inward current compared with that of the CAMP-induced current. Although experiments on unclamped cells are useful for evaluating the physiological effectiveness of the synaptic input, they are less adequate than voltage-clamp experiments for analyzing the mechanisms underlying that input, because with voltage-clamped cells, it is possible to avoid inadvertently activated voltagedependent changes, as well as secondary effects on the response amplitude caused by experimentally induced or time-dependent changes in resistance of the nonsynaptic membrane. Consequently, all other experiments were performed on voltageclamped cells.

Although the slow synaptic current is more or less prominent from one preparation to another, it always shows the voltagedependence characteristic of the cationic response induced in the same cells by an intracellular injection of cAMP: either its amplitude does not change, or it diminishes with hyperpolarization. The voltage dependencies of the injection-induced and synaptically elicited inward currents are compared in Figure 2. From the negative slope of the $\mathrm{I} / \mathrm{V}$ curve over the voltage range tested, it is clear that, around resting potential $(-50$ to -40 $\mathrm{mV}$ ), the membrane resistance is increased rather than decreased during the slow synaptic response. Consequently, this response, which couples a membrane depolarization with an increase in membrane resistance, can markedly increase the excitability of the cell, and thereby the efficacy of other incoming excitatory inputs.

Limitations on the experimental comparison of the CAMPinduced and synaptically activated slow inward current. Unfortunately, it was technically impossible to perform some of the tests that would be appropriate for establishing, as thoroughly as possible, the identity of the mechanisms underlying the synaptically activated inward current and that elicited by an intracellular injection of cAMP. In particular, it was impossible to verify that the slow synaptic current, like the injection-induced current (Kehoe, 1990), is carried by $\mathrm{Na}$ and $\mathrm{K}$ ions, because 
Figure 2. Comparison, in voltageclamped medial cells, of the slow inward current elicited by an intracellular injection of cAMP with that elicited by firing of the blocking presynaptic neuron I (arrow). $A$, Records of responses to a $100-\mathrm{nA}, 8-\mathrm{sec}$ injection of cAMP at 4 holding potentials. $B$, Synaptic currents, recorded at the same holding potentials, elicited by a 1-sec stimulation of presynaptic neuron I (note that the rapid clements of the response have been truncated for more effective illustration of the slow element of the response). $C$, A graphis comparison of the voltage dependence of the injection-induced and synaptically induced slow inward currents presented as raw data in $A$ and $B$.
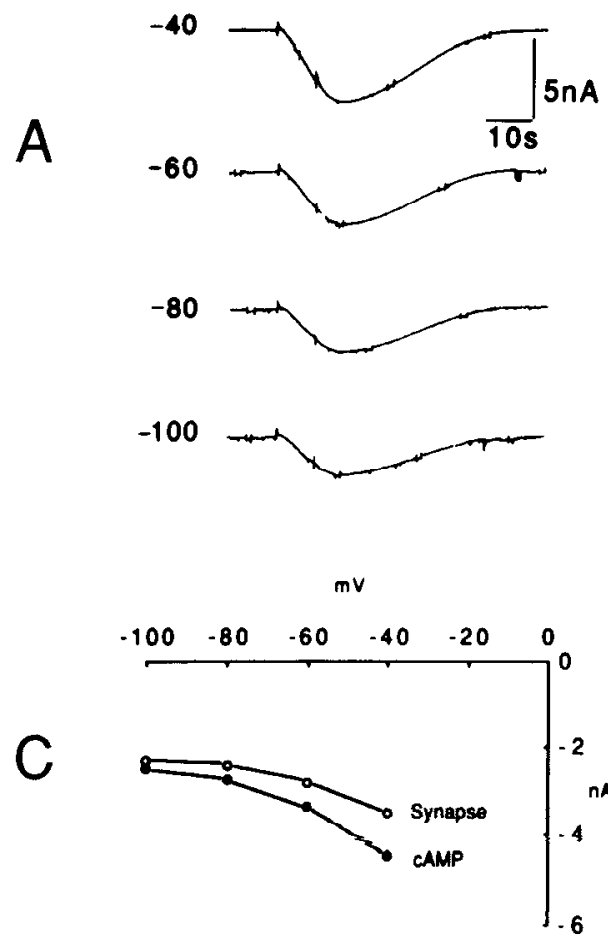

$-80$

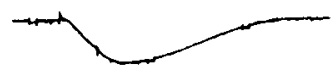

$-100$
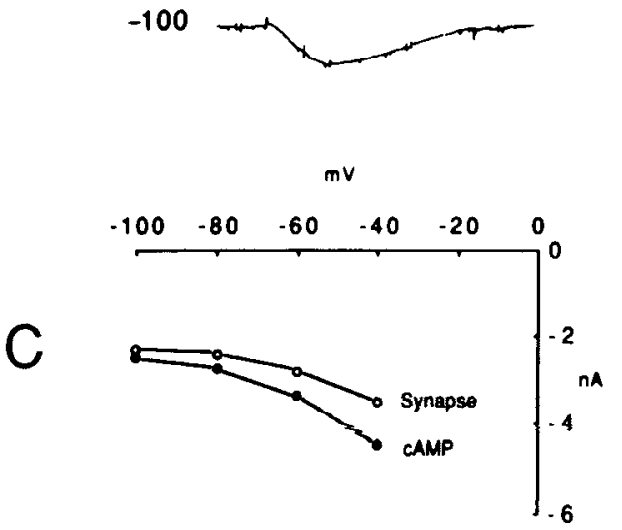

.80

60
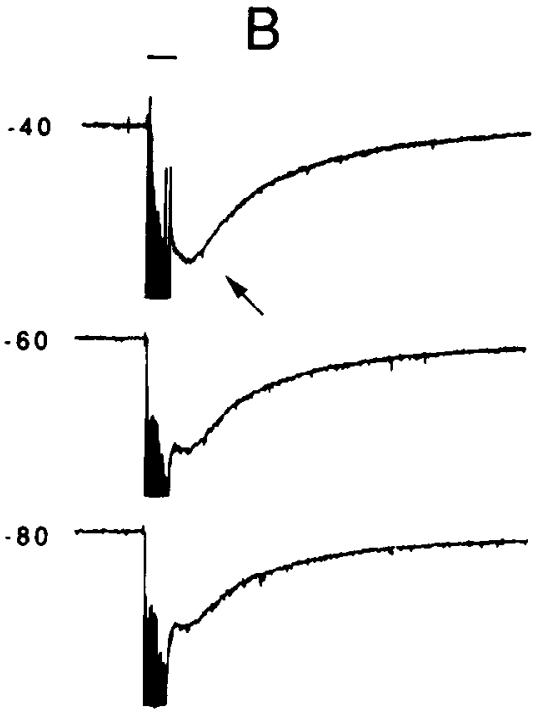

$-100$

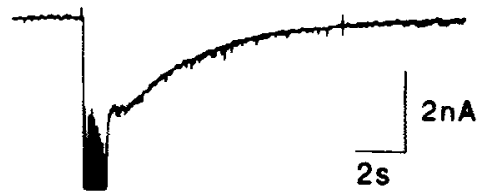

either reducing extracellular $\mathrm{Na}$ or using high- $\mathrm{KCl}$ seawater renders the presynaptic neurons inexcitable. Second, the synaptic region is far from the soma and, consequently, cannot be clamped at the positive membrane potentials at which the injectioninduced response inverts. For these reasons, no analysis of the ionic currents generating the synaptic response could be undertaken, and in the experiments designed for comparing the other characteristics of the synaptic- and injection-induced inward currents, the analyses were limited to the hyperpolarized potential range $(-40$ to $-100 \mathrm{mV})$ over which the axon is approximately isopotential with the soma. The axonic localization of the synapses also rendered impossible the pharmacological comparisons of the synaptically induced and injection-induced slow inward currents that depend upon intracellularly injected substances (e.g., it has been impossible to alter the acidity of the subsynaptic cytoplasm by intracellular injections or to apply the protein kinase inhibitor in that zone; see Kehoe, 1990).

Effects of phosphodiesterase inhibitors. The cAMP-induced response in the hyperpolarized medial cell, like that in the depolarized anterior cell, is enhanced and prolonged by phosphodiesterase inhibitors without any apparent change in the voltage dependence of the response. The effect of $100 \mu \mathrm{M}$ isobutyl-1methylxanthine (IBMX) on the injection-induced slow inward current in the hyperpolarized medial cell can be seen in Figure 3. Of the 3 inhibitors used in the experiments described here (IBMX, aminophylline, and Ro 1724), IBMX was clearly the most effective.

Differential effect of IBMX on the response to the three blocking neurons and on that activated by the nonblocking presynaptic neuron. Previous results showed that presynaptic neurons I-III imitated the blocking effect of cAMP on 2 specific $\mathrm{K}$ conductances in the medial cells, whereas presynaptic neuron $\mathrm{V}$ did not. These findings, in conjunction with others (Kehoe, 1985a, b), led to the conclusion that the 3 blocking neurons could stimulate an increase in intracellular cAMP in the medial cells, whereas the nonblocking neuron (V) could not. If indeed the responses to these different presynaptic neurons reflect the ability of 3 out of 4 of them to elicit an increase in intracellular cAMP, one would expect the responses to the 2 categories of neurons (blocking and nonblocking) to be differentially affected by phosphodiesterase inhibitors.

Figure 4 illustrates the effects of the phosphodiesterase inhibitor IBMX on the medial cell response to the 3 blocking neurons (I-III) and the 1 nonblocking neuron (V). The control records of Figure 4 reveal the presence of a slow inward current measured in voltage-clamped medial cells in response to firing of the 3 blocking neurons; this current corresponds to the slow depolarizing waves seen above in records from unclamped neurons (Fig. 1). Again, the nonblocking neuron fails to elicit the slow element of the response (Fig. 4, control records). Furthermore, Figure 4 shows that, whereas the responses to the blocking neurons were transformed by the phosphodiesterase inhibitor (Fig. 4I-III, IBMX), which selectively enhanced and prolonged the slow inward wave, the response to the control, nonblocking neuron was unaffected (Fig. $4 \mathrm{~V}$, IBMX). The records of Figure 4 also reveal the differential voltage dependence of the 2 types of excitatory synaptic currents elicited by the blocking neurons: whereas the rapid EPSCs, associated one-to-one with action potentials in the presynaptic neurons (not shown), increase with hyperpolarization of the postsynaptic cells, the slow inward current decreases. The atypical voltage dependence of the slow inward current implies that, during its activation, the input resistance of the cells is increased, rather than decreased, rendering the depolarization it would induce in the unclamped medial cell doubly effective in increasing the excitability of that cell.

Effects of intracellular acidification on the CAMP-induced and synaptically activated slow inward current. Intracellular acidification was previously shown to enhance the cAMP-induced slow inward current seen in molluscan neurons (see Aldenhoff 
et al., 1983; Green and Gillette, 1988; Kehoe, 1990). Figure $5 B$ illustrates similar findings concerning the cAMP-induced response in the hyperpolarized medial cells and shows that a similar transformation in the synaptically activatcd slow inward current (Fig. $5 A$ ) occurs upon intracellular acidification. In Figure $5, A$ and $B$, this change in intracellular $\mathrm{pH}$ was produced by exposing the cell to, and then washing out, $25 \mathrm{mM} \mathrm{NH}_{4} \mathrm{Cl}$ (see Green and Gillette, 1988). Similar effects were observed on the slow inward current elicited by the other 2 blocking neurons (not illustrated). In contrast, intracellular acidification failed to provoke a transformation in the response to presynaptic neuron $\mathrm{V}$ (not shown here), for which there is no suggestion of cAMP activation.

An intracellular somatic injection of $\mathrm{H}^{+}$ions does not seem to alter the cytoplasmic $\mathrm{pH}$ at the distant axonal subsynaptic zone, because it has been impossible to alter the synaptic response by a somatic injection of $\mathrm{H}^{+}$ions. Such an injection clearly does, however, modify the response to somatically applied cAMP (see Fig. 5C; Kehoe, 1990).

Effect of caffeine. The cationic current induced by cAMP in the anterior cells was shown in the preceding paper (Kehoe, 1990) to be enhanced by extracellular caffeine. As can be seen in Figure 6, a similar long-lasting effect of caffeine was observed on the medial cell slow inward current, whether activated by an intracellular injection of cAMP (Fig. $6 \mathrm{~A}$ ) or by firing one of the presynaptic blocking neurons (Fig. $6 B$ ). Only records from presynaptic neuron $I$ are presented, though similar findings were obtained with the other 2 blocking neurons, and, once again, even after prolonged exposure to caffeine-containing seawater, no slow inward current could be detected in response to firing of the nonblocking presynaptic neuron (i.e., presynaptic neuron $\mathrm{V}$; records not shown).

Effects of varying $(\mathrm{Ca})_{0}$ on the $C A M P$-induced response of hyperpolarized medial cells to $C A M P$. Changes in external Ca concentration were shown in the preceding paper (Kehoe, 1990) to affect markedly the cAMP-induced response in the anterior cells. Similar effects of changing external Ca concentration are seen in the cAMP-induced inward current in the hyperpolarized medial cells. In the experiments illustrated in Figure $7,(\mathrm{Ca})_{0}$ was only lowered to $1 \mathrm{~mm}$. Nevertheless, even without completely eliminating the external $\mathrm{Ca}$, there was a clear enhancement of the response, as can be seen in Figure $7 \mathrm{~A}$. In contrast, raising external $(\mathrm{Ca})_{0}$ caused a marked diminution of the response (Fig. $7 B$ ). The voltage dependence was only slightly modified under these experimental conditions $\left[25 \mathrm{~min}\right.$ exposure to $1 \mathrm{mM}(\mathrm{Ca})_{0}$; 14 min exposure to $60 \mathrm{~mm}(\mathrm{Ca})_{0}$ ].

Effect of altering $(\mathrm{Ca})_{0}$ on the synaptically elicited slow inward current. Changes seen in synaptic response amplitude can reflect either pre- or postsynaptic effects. However, because chemically transmitted responses should be reduced by low-Ca (or $\mathrm{Ca}$-free) solutions, any increase in those responses in low-Ca seawater must indicate a postsynaptic interaction, as should a decrease in high-Ca solutions (see Discussion).

Indeed, the transformation that is observed in the synaptically activated inward current is contrary to that anticipated by the effects of $(\mathrm{Ca})_{0}$ on release; that is, the slow inward current increases in low-Ca and decreases in high-Ca solutions. This paradoxical effect (in terms of release processes) can be seen in the records of the medial cell response to presynaptic neuron $I$ in low- and high-Ca seawater (see Fig. 8). The effect of lowering extracellular $\mathrm{Ca}$ on release is reflected in the reduced amplitude of the rapid EPSC (after a 30-min exposure). In spite of this clear diminution in release due to the low-Ca solution, there

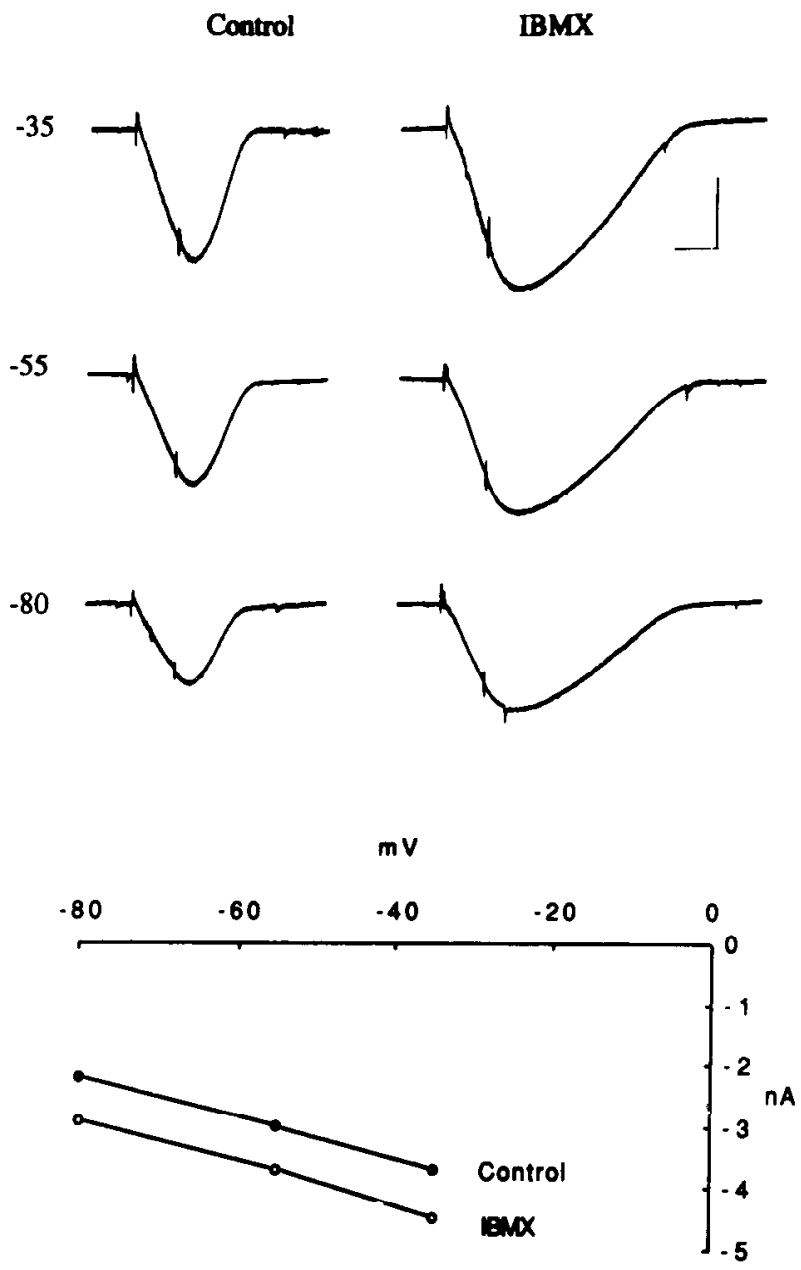

Figure 3. Effect of the phosphodiesterase inhibitor IBMX on the cAMPinduced response in a hyperpolarized medial cell. Note the increase in amplitude and duration of the response after a 16-min exposure to 100 $\mu \mathrm{M}$ IBMX and the apparent failure of this transformation to alter the voltage dependence of the response (see graph, bottom). Calibration: 2 $\mathrm{nA}, 10$ scc. cAMP injection parameters: $100 \mathrm{nA}, 10 \mathrm{sec}$.

was a marked and progressive increase in the size of the slow inward current elicited by the same presynaptic neuron (10-30 min; see Fig. 8A). In contrast (Fig. $8 B$ ), when the extracellular Ca concentration was raised (by replacing the normal $50 \mathrm{~mm}$ $\mathrm{Mg}$ by $\mathrm{Ca}$ ), there was almost a complete block of the slow inward current. The block of the slow inward current by high-Ca seawater contrasts with the clear enhancement produced in the rapid EPSC elicited by the same neuron (see Fig. $8 B, I$ ). A similar high-Ca experiment, illustrated in Figure $8 B$, II, was performed on another ganglion, but prior to changes in extracellular $\mathrm{Ca}$, the synaptic response was enhanced by an injection of TEA in the presynaptic neuron (which, by blocking the delayed rectifier in the presynaptic cell, increases the duration of its action potential and hence the release of transmitter). Both the rapid and slow elements of the response were markedly increased due to the TEA-induced increase in release from the presynaptic terminals, rendering the blockade of the slow inward current in high-Ca seawater more striking (Fig. $8 B$, II). The failure of high external $\mathrm{Ca}$ to enhance the rapid EPSC in Figure $8 B$, II, likely indicates that the pretreatment of the presynaptic neuron with TEA had saturated the release process.

Similar experiments performed with the 2 other presynaptic 


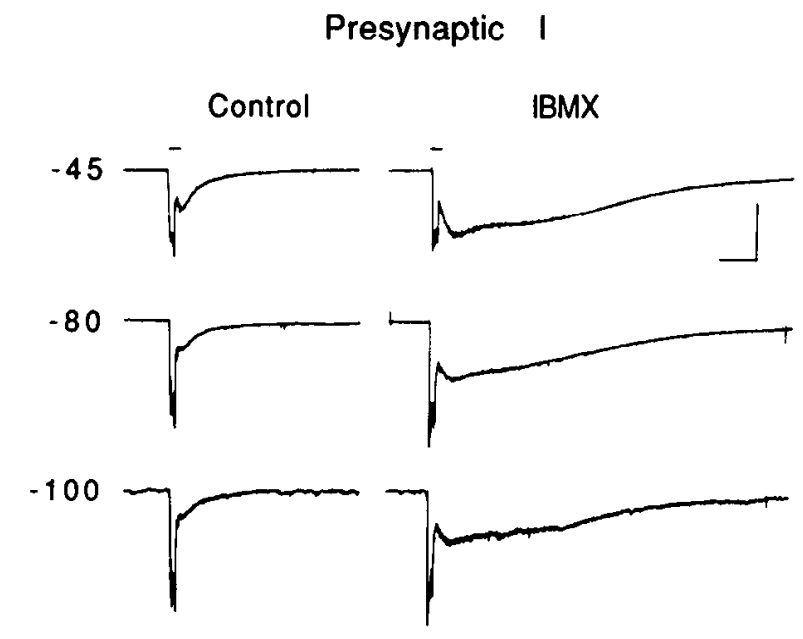

Presynaptic III

\section{Control}
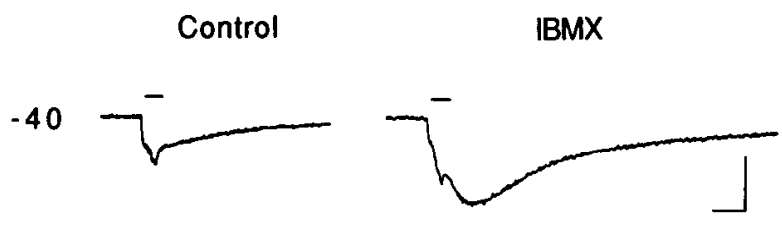

$-80$
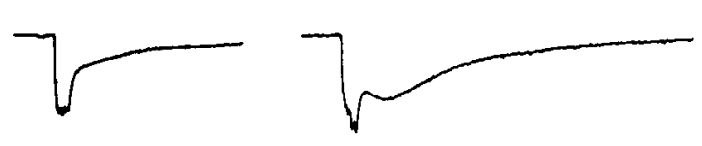

Presynaptic II

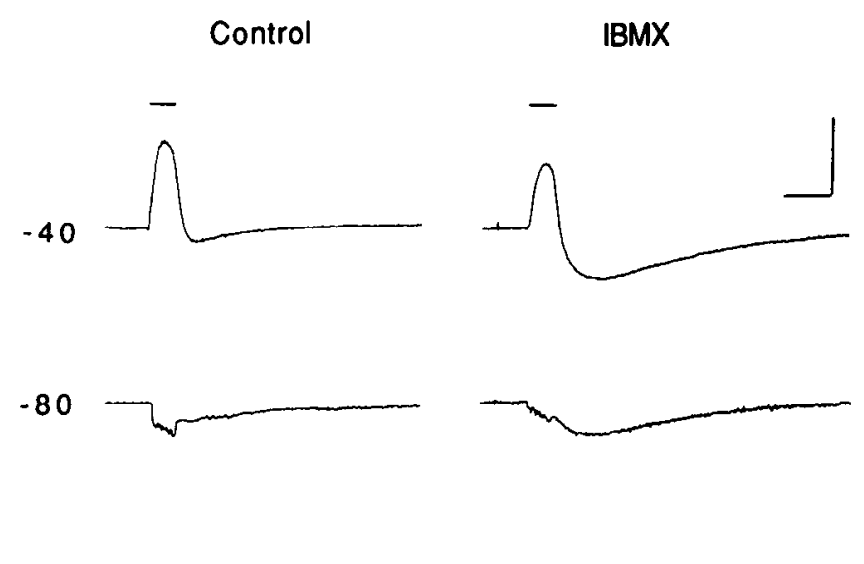

Presynaptic V

Control IBMX
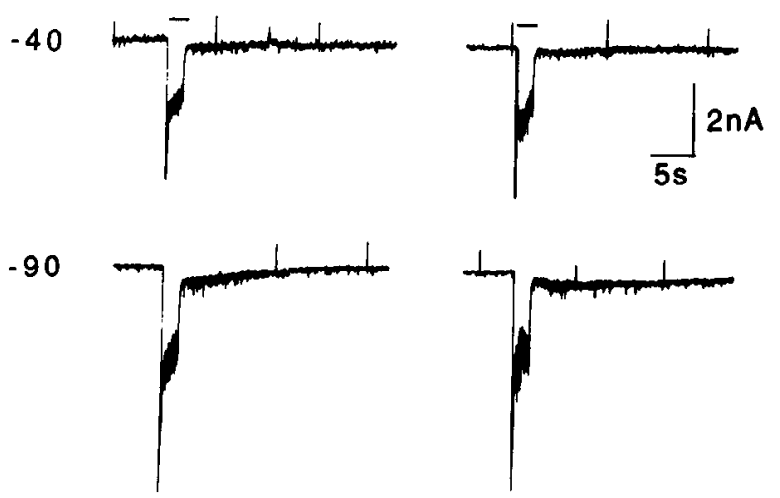

Figure 4. Effects of IBMX on responses to presynaptic neurons I-III and V recorded in voltage-clamped medial cells. The presynaptic blocking neurons (I-III) each trigger a slow inward current in the medial cells. The slow synaptic current, which corresponds to the slow depolarization seen in the unclamped cell (see Fig. 1), is markedly enhanced and prolonged by IBMX. In contrast, the nonblocking presynaptic neuron V fails to elicit the slow inward current. Furthermore, there is no transformation of the response to that presynaptic neuron in the presence of IBMX. Bars over records indicate the duration of presynaptic firing. Calibration: $2 \mathrm{nA}, 5 \mathrm{sec}$ for all 4 sets of records.

blocking neurons (presynaptic II and III) are shown in Figure 9. As can be seen in Figure $9 I I$, raising $(\mathrm{Ca})_{0}$ blocks the slow inward synaptic current. [Little effect of high $(\mathrm{Ca})_{0}$ is seen on the $\mathrm{K}$ conductance increase due to a previously described inhibitory effect of $\mathrm{Ca}$ ions on transmitter-induced $\mathrm{K}$ conductances (Chesnoy-Marchais and Ascher, 1983) that counteracts the Ca-induced increase in transmitter release.] Ca-free seawater, in contrast, causes a marked increase in the slow inward synaptic current (see Fig. 9II, third row). The initial net increase in the inward current $(400 \mathrm{sec}, 600 \mathrm{sec})$ precedes the eventual elimination of all elements of the response, the inward current included, due to the eventual failure in chemical transmission (see Fig. $9 I I, 1000 \mathrm{sec}$ ). The effect of $0 \mathrm{~mm}(\mathrm{Ca})_{0}$ on transmitter release is evident even at early exposure times (400-1000 sec), reflected as a diminution in the outward-going $\mathrm{K}$-dependent element of the response (see Kehoe, 1972a, 1985a).

The records presented from experiments on presynaptic neuron III in Figure 9 are incomplete; that is, no data have been obtained in high $(\mathrm{Ca})_{0}$. This is due to the fact that such solutions render that presynaptic neuron inexcitable, and, hence, the effect of high-Ca seawater on the slow inward current elicited by that synapse cannot be tested. However, it can be seen that low-Ca solutions clearly increase that current, as they did the equivalent current elicited by the other 2 blocking neurons. The early rapid response, on the other hand, diminishes because of the effect on the release process. The initial enhancement of the slow element is, of course, eventually overridden by the diminution in all elements of the response caused by the failure of synaptic transmission in Ca-free seawater.

Finally, a similar study of the effects of external Ca concentration on the nonblocking (control) neuron reveals once again that, even under conditions that amplify the slow inward current elicited by the blocking neurons, there is no sign of such a current in response to the activation of the nonblocking synapse (Fig. $9 \mathrm{~V}$ ). Although the Ca-free seawater has clearly reached the synaptic zone, as reflected in the diminished EPSCs, there is no appearance of a slow inward synaptic current in response to the firing of presynaptic neuron $\mathrm{V}$. 
A
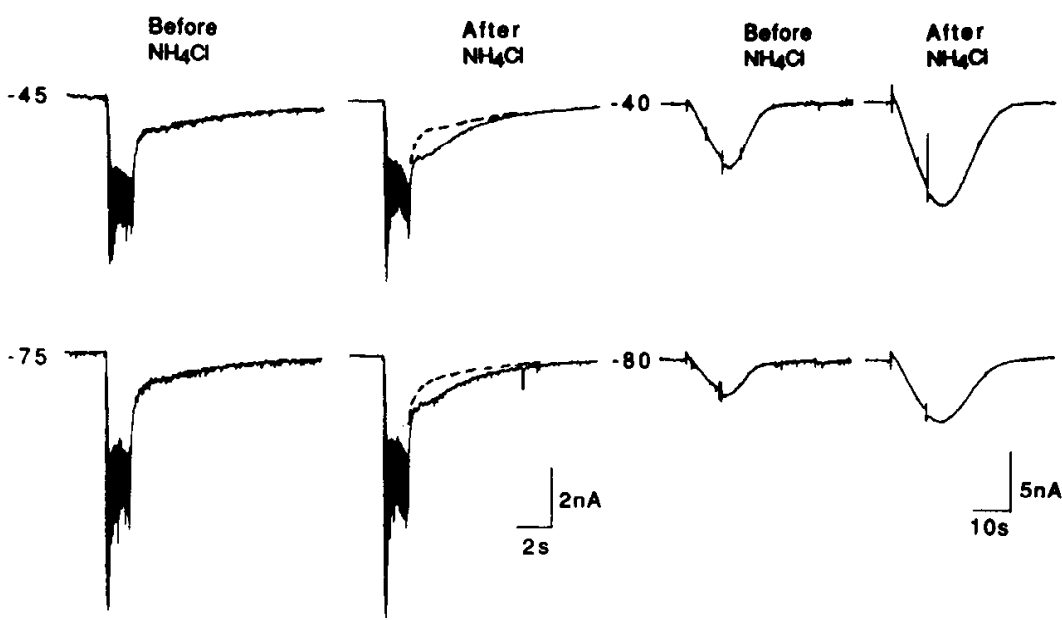

C

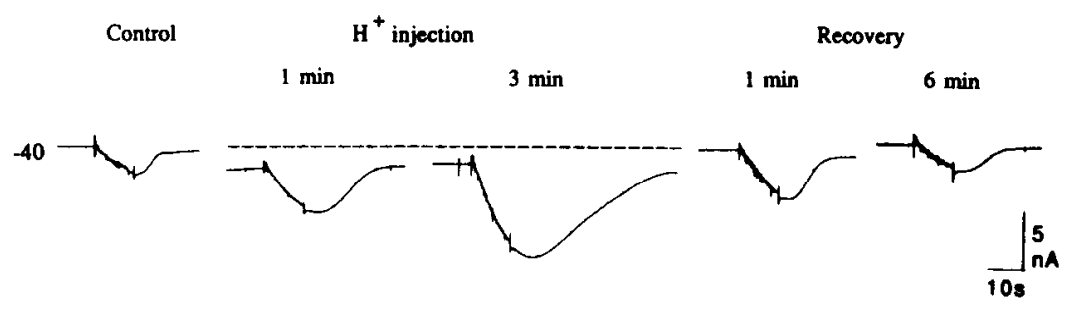

A

Control

Caffeine (2 mM)

$-60$
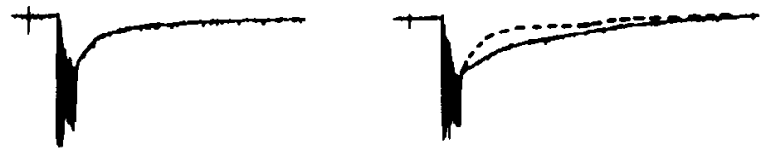

$-90$
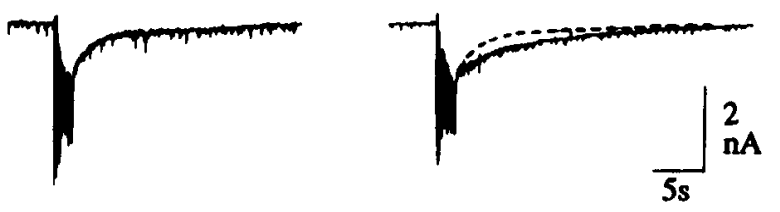

B

Control

\section{2 nil Caffeine}

$22 \mathrm{~min}$.

Wash

$60 \mathrm{~min}$.

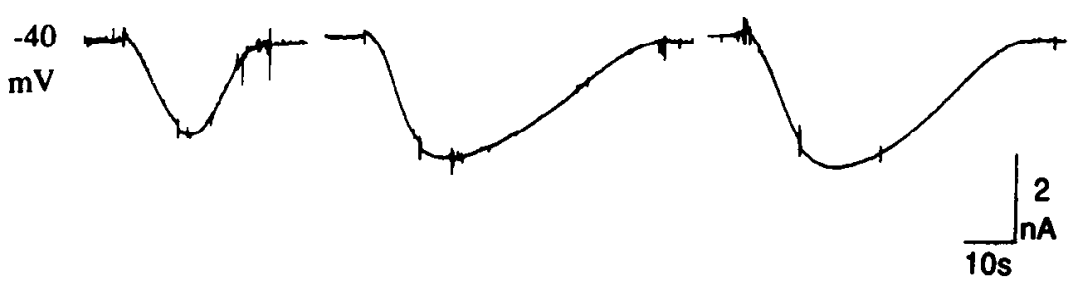

Figure 5. Effect of acidification of the cytoplasm of medial cells on the slow inward current elicited in those cells by firing of presynaptic neuron I $(A)$ or by an injection of $\operatorname{cAMP}(B, C)$. As can be seen in $B$, preexposure of the cell to 25 $\mathrm{mM} \mathrm{NH}_{4} \mathrm{Cl}(B ; 15$-min exposure, 15 min wash) causes an enhancement of the cAMP-induced inward current. This means of acidification had a similar effect in the synaptically activated slow inward current $(A ; 10$ min exposure, 10 min wash; $25 \mathrm{~mm} \mathrm{NH}_{4} \mathrm{Cl}$ ). The dashed lines are a transcription of the control slow inward current indicated for an easier evaluation of the acidificationinduced prolongation of that current. Note that the classical EPSCs are unchanged. As can be seen in $C$, an injection of $\mathrm{H}^{+}$into the soma of the medial cell enhanced the cAMP-induced current but had no effect on the synaptic response (not shown), presumably because the acidification thus induced is limited to the zone of injection (soma) and does not alter the intracellular $\mathrm{pH}$ in the subsynaptic axonal region. cAMP injection parameters: $B: 80 \mathrm{nA}, 10 \mathrm{sec}$; $C: 100 \mathrm{nA}, 11 \mathrm{sec}$.
Figure 6. Effect of 2 mм caffeine on the slow inward current elicited by firing of presynaptic neuron I $(A)$ or by an intracellularinjection of CAMP $(B)$. Caffeine can be seen to enhance the response, whether it be activated synaptically or by exogeneously applied cAMP. The dashed lines are a transcription of the control slow inward current for an easier evaluation of the caffeine-induced prolongation of that current. Note that the classical EPSCs are unchanged. The caffeine-induced enhancement is not easily reversible. cAMP injection parameters: $100 \mathrm{nA}, 11 \mathrm{sec}$. 
A

Figure 7. Effect of external $\mathrm{Ca}$ concentration on the cAMP-induced response of hyperpolarized medial cells. $A$, A reduction in $(\mathrm{Ca})_{0}$ from 10 to 1 mM (25-min exposure) causes a net enhancement of the cAMP-induced inward current without noticeably changing the voltage dependence of the response. $B$, An increase in $(\mathrm{Ca})_{0}$ from 10 to $60 \mathrm{~mm}$ (14-min exposure) causes a net decrease in the response with only a slight change in its characteristic voltage dependence. cAMP injection parameters: $A: 100 \mathrm{nA}, 7 \mathrm{sec} ; B: 100 \mathrm{nA}$, $10 \mathrm{sec}$. Calibration: $2 \mathrm{nA}, 10 \mathrm{sec}$.

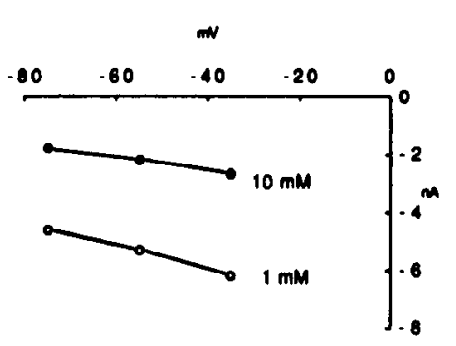

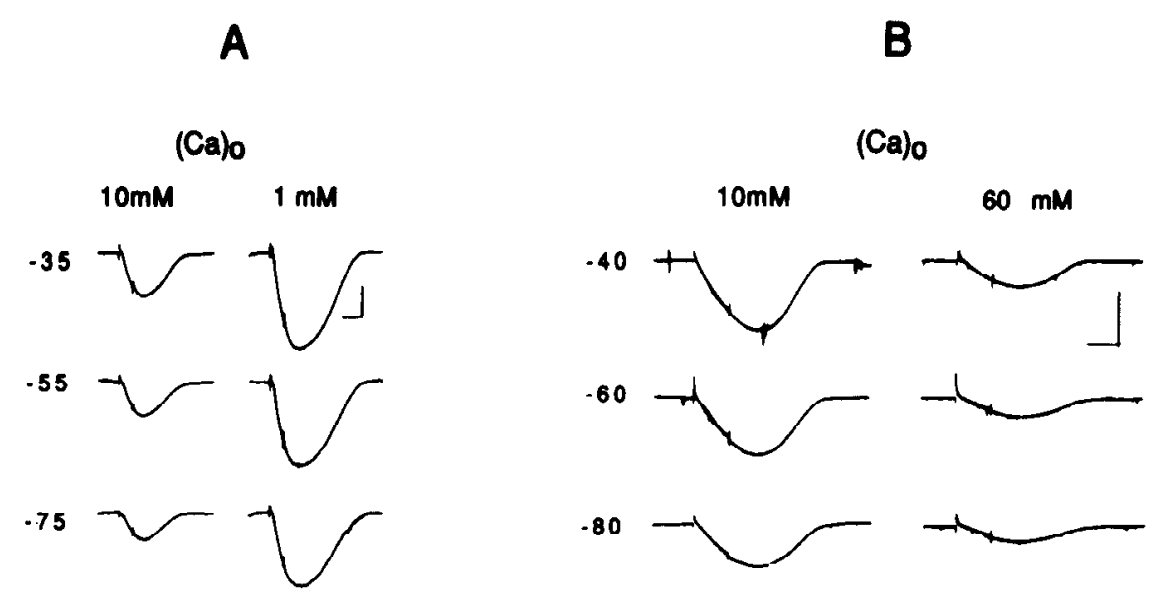

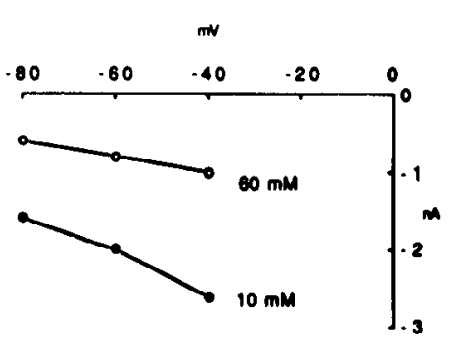

\section{Discussion}

Comparison of the slow inward current activated by an injection of CAMP and that elicited by firing of the three blocking neurons

Voltage dependence. The synaptically activated slow inward current, like the slow inward current induced by a cAMP injection, exhibits an atypical voltage dependence: for both currents, the amplitude either remains constant or diminishes with hyperpolarization. The more rapid excitatory synaptic elements elicited by the same presynaptic neurons, on the other hand, increase with hyperpolarization in the manner typical of classical transmitter-induced conductance increases. The physiological significance of this atypical voltage dependence is that during this synaptically activated, long-lasting depolarization, the input resistance of the postsynaptic cell is increased. Consequently, this synaptic response is doubly effective in increasing the excitability of the cell because it not only brings the cell closer to the firing threshold, but also increases the efficacy of incoming synaptic inputs because of the increased input resistance it induces.

Effects of inhibiting phosphodiesterase. The slow inward current elicited by the 3 blocking neurons, like that induced by an intracellular injection of cAMP, is enhanced and prolonged by phosphodiesterase inhibitors; furthermore, for both the injection-induced and synaptically activated currents, the effectiveness of the different inhibitors tested is the same, with IBMX being far more effective than either aminophylline or Ro 1724 . Bath-applied caffeine and intracellular acidification, both previously shown to inhibit phosphodiesterase (Butcher and Sutherland, 1962; Calhoon and Gillette, 1983), likewise prolong both the synaptically activated and the injection-induced current. However, it cannot be excluded that intracellular acidification might not also exert effects on this current through other, more direct means (see Kehoe, 1990). What is of importance here is that the injection-induced and synaptically elicited currents are affected in the same way by all of these manipulations.

Effect of changes in $(\mathrm{Ca})_{0}$. The similarity of the injectioninduced and synaptically activated slow inward currents is also reflected in the response of the 2 currents to changes in extracellular $\mathrm{Ca}$ concentration. In spite of the fact that all elements of the responses to the presynaptic neurons used here are chemically rather than electrically mediated, the slow inward synaptic current, like the slow injection-induced current, is initially enhanced in low-Ca solutions and blocked by high-Ca solutions, contrary to what is expected from the effects of $(\mathrm{Ca})_{0}$ on the release of transmitter. However, it should be recalled that, after the initial enhancement of the slow synaptic inward current in low-Ca or Ca-free solutions, there follows a progressive decline in that current that coincides with a continued decline and eventual disappearance of all elements of the synaptic responses (see Fig. 9). The marked similarity of the initial effects of $(\mathrm{Ca})_{0}$ on the synaptically induced and injection-induced current, the latter of which does not depend on transmitter release, strongly suggests that the seemingly paradoxical effects of external $\mathrm{Ca}$ on the synaptic response simply reflect a dominance of the postsynaptic modulatory effect of $(\mathrm{Ca})_{0}$ over its concomitant presynaptic effect. It is certain that $(\mathrm{Ca})_{0}$ needs to be lowered significantly before the liberation is affected, and for significant changes of concentration to occur at the presynaptic terminals, long exposures to low-Ca seawater are necessary [see Fig. 8; a reduction in transmitter release was evident only after a 30 -min 
A

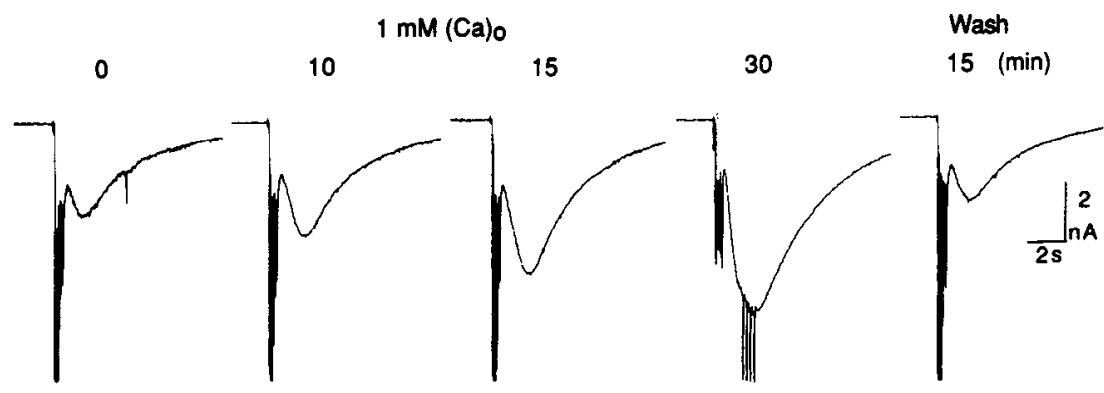

B

1
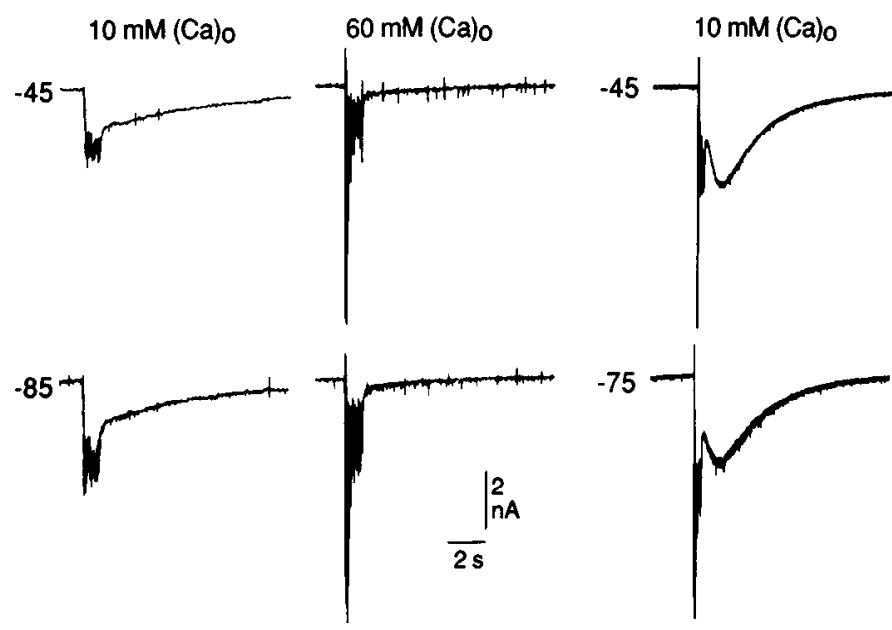

$\|$

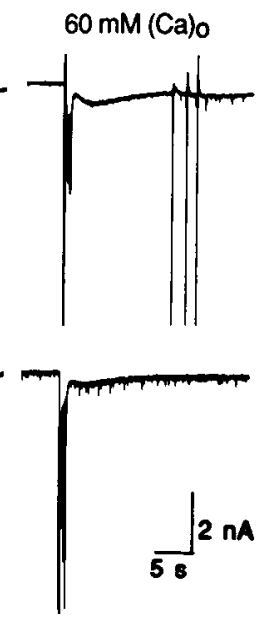

Figure 8. Effect of $(\mathrm{Ca})_{0}$ on the amplitude of the slow inward current activated in the medial cells by firing of presynaptic neuron I. (Because the rapid postsynaptic currents are associated one-to-one with presynaptic action potentials, the duration of presynaptic firing is evident from the postsynaptic records.) $A$, Effect of reducing $(\mathrm{Ca})_{0}$ from 10 to $1 \mathrm{~mm}$. Note the progressive increase in the slow inward current over time of exposure to $1 \mathrm{~mm}(\mathrm{Ca})_{0}$ in spite of the diminution in transmitter release (revealed by the reduction in the amplitude of the rapid element of the synaptic response after a 30-min exposure). Presynaptic firing duration; 0.5 sec. $B$, Effect of increasing $(\mathrm{Ca})_{0}$ from 10 to $60 \mathrm{~mm}$. $I$, High-Ca seawater causes a reduction of the slow inward current in spite of an increase in transmitter release as evidenced by an increased amplitude of the classical EPSCs. II, Reduction by high-Ca seawater of the slow inward current element of an experimentally enhanced synaptic response. (Prior to changing (Ca) ${ }_{0}$, transmitter release was increased by injecting TEA into the presynaptic neuron; see text.) Presynaptic firing duration in $I$ and $I I, 1 \mathrm{sec}$. exposure to $\left.1 \mathrm{~mm}(\mathrm{Ca})_{0}\right]$. These factors probably explain the initial dominance of the postsynaptic effect of $(\mathrm{Ca})_{0}$ over its effects on transmitter liberation.

However, one other possible interpretation of the seemingly paradoxical effects of external Ca must be considered. It is known that the firing threshold of neurons is markedly affected by the external concentration of $\mathrm{Ca}$, and lowering $(\mathrm{Ca})_{0}$ would be expected to facilitate any possible involvement of interneurons in the development of the synaptic response, whereas raising $(\mathrm{Ca})_{0}$ would eliminate such a participation. Consequently, the effects of $(\mathrm{Ca})_{0}$ observed here might indicate that the synaptic connections underlying the slow inward current are multi- rather than monosynaptic. Such an explanation seems unlikely, because all other tests previously made on the slow synaptic element of the response, as well as on the other, more classical elements, strongly suggest that all elements of all the synaptic responses studied here are mediated monosynaptically. The monosynapticity of a given element of a synaptic response in a ganglionic preparation can never be unequivocally proven; however, a series of verifications were made for each of these synapses (Kehoe, 1985a, b), similar to those illustrated for another identifiable synaptic connection (Kehoe, 1972c) in order to determine as conclusively as possible the monosynaptic nature of these responses. It was shown that there was a progressive and correlated increase of all elements of the response to each of the neurons when trans- mitter release was increased by a progressive injection of TEA in a given presynaptic neuron. Furthermore, it was shown that each element of each of the responses maintains a characteristic and constant latency with repeated firing of the presynaptic neuron involved. The additional demonstration, used previously (Kehoe, 1972c), of a concomitant and progressive decrease in all elements of the response with low-Ca solutions, or a concomitant and progressive increase in high-Ca solutions, obviously does not hold for the slow inward current described here, at least over the initial period of exposure to a changed concentration of $(\mathrm{Ca})_{0}$, because low $\mathrm{Ca}$ enhances and high $\mathrm{Ca}$ diminishes that element of the response. However, all the data taken together strongly suggest that, rather than implicating a multisynaptic origin of the slow inward current, the paradoxical effect of $(\mathrm{Ca})_{0}$ on the slow synaptic response simply reflects, as was mentioned above, the initial dominance of the postsynaptic modulation by $(\mathrm{Ca})_{0}$ of the slow inward current over the more slowly developing effect of this divalent on transmitter release.

\section{The synaptically activated slow inward current is mediated by} a synaptically induced increase in cAMP

All of the above parallels between the 2 currents [effects of voltage, phosphodiesterase inhibitors, caffeine, intracellular acidification, and $(\mathrm{Ca})_{0}$ ] suggest that activation of endogenous cAMP underlies the synaptically activated slow inward current. 
Presynaptic ॥

(Ca)o

Figure 9. Effect of changes in $(\mathrm{Ca})_{o}$ on the synaptic responses elicited by firing of presynaplic neurons II, III, and V. Presynaptic II: Upper records, An increase in $(\mathrm{Ca})_{0}$ from 10 to $60 \mathrm{~mm}$ blocks the slow inward current activated by presynaptic neuron II. Lower records, $\mathrm{Ca}$-free seawater first causes a marked enhancement of the slow inward current. This enhancement is temporary, however, hecause the Ca-free solutions eventually block transmitter release, as indicated by the eventual disappearance of all elements of the synaptic response. Presynaptic III, A 10-min exposure to Ca-free seawater causes a similar increase in the slow inward current and a decrease in the classical EPSCs elicited by presynaptic neuron III. These changes are followed by the eventual disappearance (not shown) of all elements of the response due to the effects of Ca-free seawater on transmitter release. Presynaptic $V$, The amplitude of the FPSCs elicited by firing presynaptic neuron $\mathrm{V}$ was markedly reduced after 5 min exposure to Ca-free seawater, but there was no sign of a slow inward current, even in low $\mathrm{Ca}$. The response was almost completely eliminated after 15 min Ca deprivation (not shown). Duration of presynaptic firing is indicated by bars placed above the postsynaptic responses.

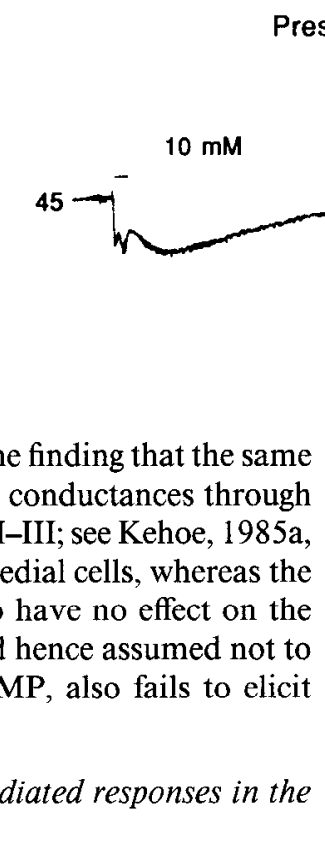

Presynaptic III

(Ca)o

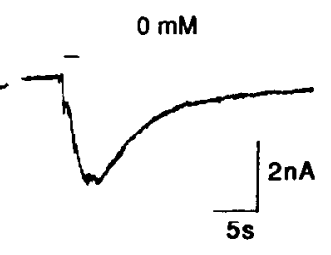

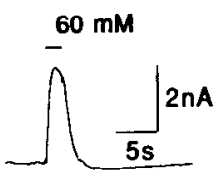

$80 \mathrm{mV} \longrightarrow$

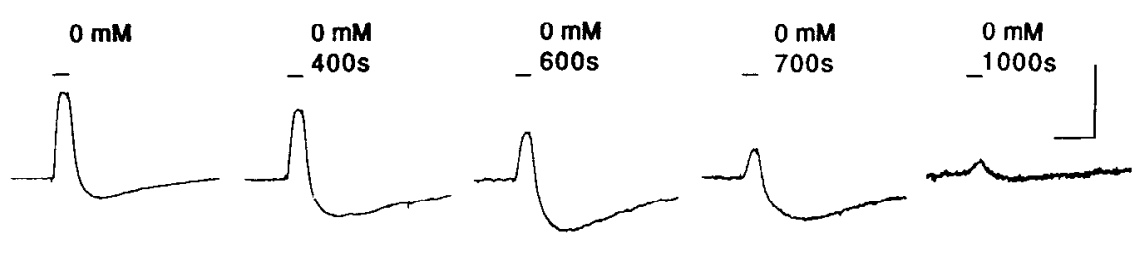

This conclusion is also strengthened by the finding that the same presynaptic neurons found to block $2 \mathrm{~K}$ conductances through a cAMP-dependent mechanism (neurons I-III; see Kehoe, 1985a, b) elicit the slow inward current in the medial cells, whereas the presynaptic neuron previously shown to have no effect on the relevant $\mathrm{K}$ conductances (neuron $\mathrm{V}$ ), and hence assumed not to produce an increase in intracellular cAMP, also fails to elicit the slow inward current.

\section{Possible functional role of the $C A M P$-mediated responses in the medial cells}

The slow inward synaptic current described here is thus 1 of 3 cAMP-mediated slow excitatory responses elicited by the blocking neurons in the medial cells. The other 2 slow excitatory responses previously described (Kehoe, $1985 \mathrm{a}, \mathrm{b}$ ) reflect cAMPmediated diminutions in 2 distinct $K$ conductances: one, a transmitter-induced $\mathrm{K}$ conductance; the other, a TEA-insensitive, Ca-activated one (Fig. 10).

When neither of the cAMP-sensitive $\mathrm{K}$ conductances is activated, which appears to be the usual case at resting potential in cells in the isolated ganglion, the blocking neurons elicit only one slow synaptic response: a depolarization that is associated, around resting potential, with an increase in membrane resistance (see Fig. 1, $-40 \mathrm{mV}$; Kehoe, 1990). When either of the 2 cAMP-sensitive $\mathrm{K}$ conductances is activated (e.g., during the firing of cholinergic presynaptic neurons or after depolarizationinduced entrance of $\mathrm{Ca}$ ), the blocking neurons also elicit a depolarizing potential that reflects a diminution in $\mathrm{K}$ conductance. Consequently all 3 synaptic inputs increase the input resistance and at the same time bring the medial cell closer to firing threshold, thereby increasing the effectiveness of other incoming synaptic potentials. Furthermore, the synaptically activated increase in cAMP counteracts, in an active and direct way, inhibitory effects due either to cholinergic input or to an influx of $\mathrm{Ca}$. The increased excitability thus associated with the cAMPmediated responses elicited by the 3 blocking neurons can last for up to the minute range and hence can have a pronounced effect on synaptic integration in the medial cells.

Although this is the first demonstration of a synaptic activation of the cAMP-mediated slow inward current in molluscan cells (see, however, Gillette, 1984), exogeneously applied transmitters have been shown to activate a similar current in other Aplysia neurons. Matsumoto et al. (1988) observed a similar cAMP-mediated current in response to exogeneously applied dopamine, and Taussig et al. (1989), in response to serotonin or the small cardioactive peptide $\mathrm{SCP}_{\mathbf{b}}$. Ichinose and McAdoo $(1988,1989)$ have observed a response with similar characteristics that is activated by FMRFamide but appears to be mediated by cGMP. A similar current was also shown to be activatcd in other Aplysia cells by egg-laying hormone (Scheller and Kirk, 1987), though no tests were made concerning an involvement of cyclic nucleotides.

\section{Which transmitters are inducing the synaptically activated increase in cAMP?}

It is clear that the different classical PSPs elicited by the 3 different blocking neurons are due to the liberation of different transmitters (see Fig. 1; Kehoe, 1985a, b). It has been concluded 


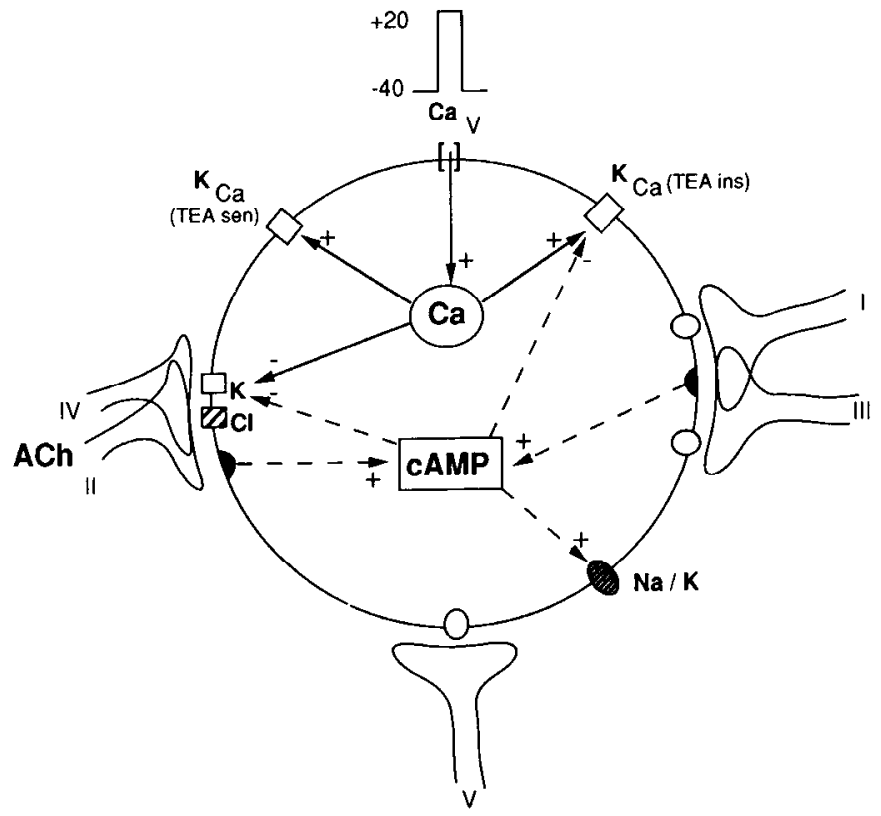

Figure 10. Schematic presentation of Ca- and CAMP-mediated changes in membrane conductance in medial cells: relation of these changes to slow excitatory responses elicited in the same cells by 5 monosynaptically connected presynaptic neurons.

$\mathrm{Ca}$-induced changes in membrane conductance. It has been shown previously (Kehoe, 1985b) that a depolarization-induced influx of $\mathrm{Ca}$ in the medial cells $\left(\mathrm{Ca}_{V}\right)$ activates 2 pharmacologically distinct $\mathrm{K}$ conductances (solid line, "+" arrow leading to rectangular-shaped membrane channels): one blocked by $1 \mathrm{mM}$ TEA $\left(K_{C a}, T E A\right.$ sen); the other, unaffected by $10 \mathrm{mM}$ TEA $\left(K_{C a}, T E A\right.$ ins). This Ca influx has also been shown to inhibit a cholinergic K conductance (solid line, "- " arrow leading to rectangular-shaped membrane channel) activated by presynaptic neurons IV and II. [Note that ACh also activates an increase in $\mathrm{Cl}$ conductance (striated, rectangular-shaped membrane channels) controlled by a pharmacologically distinct cholinergic receptor.]

cAMP-induced diminutions in $K$ conductances. It has also been shown (Kehoe, 1985a, b) that 3 blocking neurons (I-III) stimulate an increase in intracellular cAMP (see blackened demi-circles associated with dashed lines, "+ "arrows leading to $C A M P$ pool), which in turn causes a diminution in both the TEA-insensitive, $\mathrm{Ca}$-activated $\mathrm{K}$ conductance and that induced by ACh (dashed lines, "- " arrows leading to rectangularshaped membrane channels). (The Ca-induced and cAMP-induced effects on the cholinergic $\mathrm{K}$ channel are assumed to be independent; see Kehoe, 1985a, b.)

cAMP-induced increase in cationic conductance. The increase in cAMP stimulated by presynaptic neurons I-III also leads to the activation of a slow cationic current described in this and a previous paper (Kehoe, 1990; dashed line, "+ " arrow leading to darkened, oval-shaped membrane channel). Other classical excitatory currents, carried by the receptor-linked channels represented by empty ovals, are also activated by presynaptic neuron I and III, as well as by presynaptic neuron V, which does not stimulate an increase in intracellular cAMP.

from earlier work (Kehoe, 1972b, 1985a) that presynaptic neuron II liberates acetylcholine, which has been shown to imitate the classical elements of the response to firing of this input. No data have been obtained that elucidate which transmitters are responsible for the classical PSPs elicited by the presynaptic neurons I, III, or V. It appears rather likely, however, in view of the common action of neurons I-III, that the CAMP-induced potential is the result of the liberation, with the "principal" transmitter, of a cotransmitter common to the 3 blocking neurons. Evidence for a concomitant liberation of acetylcholine and a small cardioactive peptide from another Aplysia cholinergic neuron has recently been presented (Cropper et al., 1988; Whim et al., 1989), and the peptide, but not acetylcholine, has been shown to elicit an increase in cAMP concentration in the muscle cells it innervates (Whim and Lloyd, 1989).

\section{Comparison of the $C A M P$-mediated synaptic current in molluscan neurons to other nucleotide-induced slow inward currents in other preparations}

All characteristics of the slow inward current described here are shared by nucleotide-induced currents described in photoreceptors (Fesenko, et al., 1985; Haynes et al., 1986; Stryer, 1986; Zimmerman and Baylor, 1986; Matthews, 1987), olfactory receptor cilia (Nakamura and Gold, 1987), and cardiac myocytes (Egan et al., 1987). As has been elaborated in more detail in the preceding paper (Kehoe, 1990), these currents all appear to be gated directly by micromolar concentrations of the appropriate nucleotide; all are increased and prolonged when phosphodiesterase is inhibited; all appear to be cationic, outwardly rectifying currents that are blocked by divalent cations; and, where testing has been possible, the amplitude of the elementary conductance of the nucleotide-gated channels appears to be the same order of magnitude (for specific references, see Hockberger and Swandulla, 1987; Kehoe, 1990). Taking into account the above findings and those presented here, it appears that this current is quite ubiquitous and plays many different roles: it is present at the sensory receptor level as well as at central synapses; it exists in vertebrate as well as in invertebrate cells; and whereas in some cases it is spontaneously active, in others it is receptor controlled.

\section{References}

Aldenhoff JB, Hofmeier G, Lux HD, Swandulla D (1983) Stimulation of a sodium influx by cAMP in Helix neurons. Brain Res 276:289296.

Butcher RW, Sutherland EW (1962) Adenosine 3,5'-phosphate in biological materials. I. Purification and properties of cyclic 3,5'-nucleotide phosphodiesterase and the use of this enzyme to characterize adenosine 3,5'-phosphate in human urine. J Biol Chem 237:12441250.

Calhoon RD, Gillette R (1983) $\mathrm{Ca}^{2+}$ activated and $\mathrm{pH}$ sensitive cyclic AMP phosphodiesterase in the nervous system of the mollusc Pleurobranchaea. Brain Res 271:371-374.

Chesnoy-Marchais D, Ascher P (1983) Effects of various cations on the slow $\mathrm{K}^{+}$conductance increases induced by carbachol, histamine and dopamine in Aplysia neurons. Brain Res 259:57-67.

Cropper EC, Miller MW, Tennenbaum R, Kolks MA, Kuppermann I, Weiss KR (1988) Structure and action of buccalin: a modulatory neuropeptide localized to an identified small carioactive peptide-containing cholinergic motor neuron of Aplysia californica. Proc Natl Acad Sci USA 85:6177-6181.

Egan TM, Noble D, Noble SJ, Powell T, Twist VW (1987) An isoprenaline activated sodium-dependent inward current in ventricular myocytes. Nature 328:634-637.

Fesenko EE, Kolesnikov SS, Lyubarsky AL (1985) Induction by cyclic GMP of cationic conductance in plasma membrane of retinal rod outer segment. Nature 313:310-313.

Gillette MLU (1984) Stimulation of chemosensory pathways and intracellular alkalinization mimic cAMP activation of endogenous bursting in feeding command neurones. J Exp Biol 111:239-245.

Gold GH, Nakamura T (1987) Cyclic nucleotide-gated conductances: a new class of ion channels mediates visual and olfactory transduction. TIPS 8:312-316.

Green DJ, Gillette R (1988) Regulation of cAMP-stimulated ion current by intracellular $\mathrm{pH}, \mathrm{Ca}^{2+}$, and calmodulin blockers. J Neurophysiol 59:248-258.

Haynes LW, Kay AR, Yau K-W (1986) Single cyclic GMP-activated channel activity in excised patches of rod outer segment membrane. Nature 321:66-70.

Hockberger PE, Swandulla D (1987) Direct ion channel gating: a new function of intracellular messengers. Cell Mol Neurobiol 7:229-236. 
Ichinose M, McAdoo DJ (1988) The voltage-dependent, slow inward current induced by the neuropeptide FMRFamide in Aplysia neuron R14. J Neurosci 8:3891-3900.

Ichinose M, McAdoo DJ (1989) The cyclic GMP-induced inward current in neuron R14 of Aplysia californica: similarity to a FMRFamide-induced inward current. J Neurobiol 20:10-24.

Kehoe JS (1972a) Ionic mechanisms of a two-component cholinergic inhibition in Aplysia neurones. J Physiol 225:85-114.

Kehoe JS (1972b) Three acetylcholine receptors in Aplysia neurones. J Physiol 225:115-146.

Kehoe JS (1972c) The physiological role of three acetylcholine receptors in synaptic transmission in Aplysia. J Physiol 225:147-172.

Kehoe JS (1985a) Synaptic block of a transmitter-induced potassium conductance in Aplysia neurones. J Physiol 369:399-437.

Kehoe JS (1985b) Synaptic block of a calcium-activated potassium conductance in Aplysia neurones. J Physiol 369:439-474.

Kehoe JS (1986) Three cyclic AMP mediated excitatory currents generated in a given Aplysia neuron by the same presynaptic cell. Soc Neurosci Abst 12:14.

Kehoe JS (1990) Cyclic AMP-induced slow inward current in depolarized neurons of Aplysia californica. J Neurosci 10:3194-3207.

Liberman EA, Minna SV, Golubtsov KV (1975) The study of the metabolic synapse. I. Effect of intracellular microinjection of $3^{\prime}, 5^{\prime}$ AMP. Biophys (Moscow) 20:451-457.
Matsumoto M, Sasaki K, Sato M, Shozushima M, Takashima K (1988) Dopamine-induced depolarizing responses associated with negative slope conductance in LB-cluster neurones of Aplysia. J Physiol 407: 199-213.

Matthews G (1987) Single-channel recordings demonstrate that cGMP opens the light-sensitive ion channel of the rod photoreceptor. Proc Natl Acad Sci USA 84:299-302.

Nakamura T, Gold GH (1987) A cyclic nucleotide-gated conductance in olfactory receptor cilia. Nature 325:442-444.

Scheller RH, Kirk MD (1987) Neuropeptides in identified Aplysia neurons: precursor structure, biosynthesis, and physiological actions. TINS 10:46-52.

Stryer L (1986) Cyclic GMP cascade of vision. Ann Rev Neurosci 9: $87-120$.

Taussig R, Sweet-Cordero A, and Scheller RH (1989) Modulation of ionic currents in Aplysia motor neuron B15 by serotonin, neuropeptides, and second messengers. J Neurosci 9:3218-3229.

Whim MD, Lloyd PE (1989) Frequency-dependent release of peptide cotransmitters from identified cholinergic motor neurons in Aplysia. J Neurosci 86:9034-9038.

Zimmerman AL, Baylor DA (1986) Cyclic GMP-sensitive conductance of retinal rods consists of aqueous pores. Nature 321:70-72. 